\title{
CONTRIBUIÇÃO AO ESTUDO DA GENITÁLIA DE FÊMEAS DE PHYTOCORIS FALLÉN (HEMIPTERA, MIRIDAE)
}

\author{
Argentino Viegas Fontes 1
}

\begin{abstract}
CONTRIBUTION TO THE STUDY OF THE FEMALE GENITALIA OF PHYTOCORIS FALLÉN (HEMIPTERA, MIRIDAE). A study of the female genitalia of eight species of Prhytocoris Fallén, 1814 is presented (Phytocoris araucanus Carvalho \& Ferreira, P. bergrothi Reuter, $\mathbf{P}$. irroratus Blanchard, P. marmoratus Blanchard, P. obsoletus Blanchard, P. parandinus Carvalho \& Ferreira, $\mathbf{P}$. rubrescens Blanchard and $\mathbf{P}$. rubrovenosus Carvalho \& Ferreira). Sclerotized rings, posterior wall of bursa copulatrix and sclerotized plate of anterior gonapophyses are illustrated.
\end{abstract}

KEY WORDS. Hemiptera, Miridae, Phytocoris, female genitalia, morphology

$\mathrm{O}$ presente trabalho dá continuidade às pesquisas que o autor vem se dedicando, no sentido de contribuir para o conhecimento da morfologia de certas estruturas esclerosadas da genitália de fêmeas de Miridae, com vistas à taxonomia do grupo.

O estudo aborda a morfologia dos anéis esclerosados, parede posterior da bolsa copuladora e placa esclerosada das gonapófises anteriores de oito espécies sul-americanas de Phytocoris Fallén, 1814. Estas espécies constam dos trabalhos de CARVALHO \& FERREIRA (1969) e CARVALHO \& GOMES (1970), nos quais a genitália das fêmeas não foi estudada.

O método seguido na dissecção das genitálias foi usado por FONTES (1981). A terminologia usada está baseada em SLATER (1950), DAVIS (1955) e FONTES (1989). As dimensões são dadas em milímetros, com aproximações de três casas decimais, obtidas através de microscópio Zeiss, objetiva com aumento de oito vezes e ocular micrométrica Zeiss de aumento de sete vezes.

\section{Phytocoris araucanus Carvalho \& Ferreira, 1969}

Figs 1, 5, 17

Anéis esclerosados (Fig. 1). Alongados, quase retangulares; margens laterais largas, as medianas, metade das anteriores e as posteriores, estreitas; com um espessamento fortemente esclerosado, estreito, nas margens anteriores dos anéis, atingindo a borda lateral da placa. Comprimento máximo 0,096; largura máxima 0,384; distância entre anéis 0,216 . Placa labiada dorsal com as bordas laterais e uma faixa estreita, ligando os espessamentos dos anéis, forte-

1) Museu Nacional do Rio de Janeiro, Quinta da Boa Vista, 20940-040 Rio de Janeiro, Rio de Janeiro, Brasil. Bolsista do CNPq. 
mente esclerosadas. Comprimento máximo 0,216; largura máxima 1,032.

Parede posterior (Fig. 5). Estruturas A com margem ventral reentrante, medianamente; metade da margem dorsal e processo dorsal, largos, fortemente esclerosados; estrutura B esclerosada, com a região anterior larga, semicircular, envolvida por lobos membranosos; região posterior retilínea até o centro das estruturas A, onde forma um tubérculo; a partir deste, torna-se divergente; estrutura $\mathrm{E}$ muito estreita. Comprimento máximo 0,264; largura máxima 0,720; estrutura B, comprimento máximo 0,264; largura máxima 0,144 .
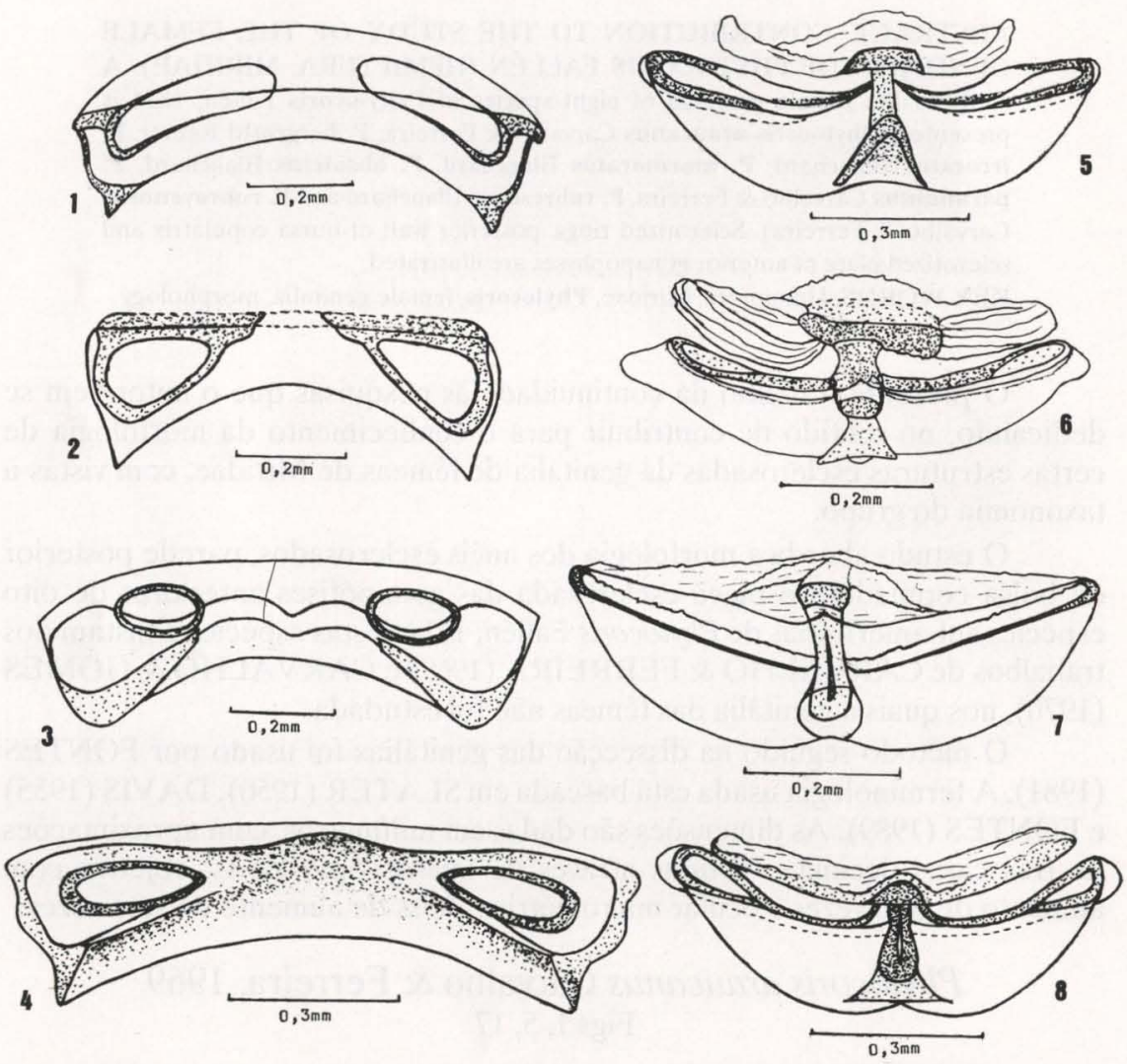

Figs 1-8. (1-4) Vista dorsal dos anéis esclerosados; (5-8) vista posterior da parede posterior; $(1,5)$ Phytocoris araucanus; $(2,6) \mathbf{P}$. bergrothi; $(3,7) \mathbf{P}$. irroratus; $(4,8) \mathbf{P}$. marmoratus.

Placa esclerosada das gonapófises (Fig. 17). Lobos laterais curvos, contendo cada um, medianamente, uma pequena estrutura em forma de grão esclerosada; lobo dorsal indefinido; lobo ventral membranoso. Comprimento máximo 0,072 ; largura máxima 0,360 .

Material examinado. Quatro fêmeas. CHILE: Las Cabras, III-1952, Kuschel leg. (parátipo, Museu Nacional do Rio de Janeiro - MNRJ). 
Localidade-tipo: CHILE, Las Cabras.

Comentário. A forma, dimensões e margens dos anéis esclerosados; a placa labiada dorsal; a estrutura B da parede posterior e a placa esclerosada das gonapófises anteriores diferenciam Phitocoris araucanus das demais espécies.
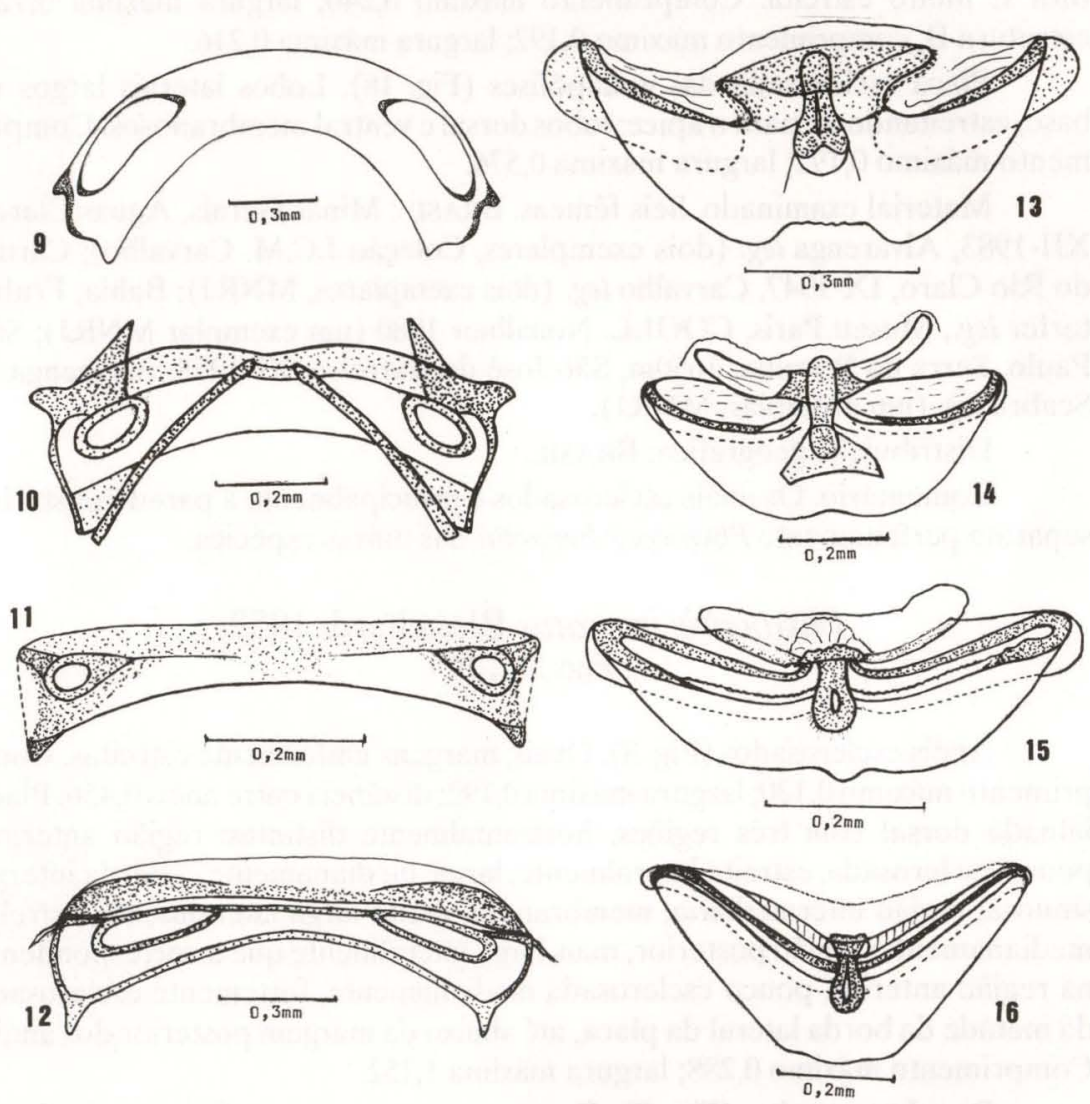

Figs 9-16. (9-12) Vista dorsal dos anéis esclerosados; (13-16) vista posterior da parede posterior; $(9,13)$ Phytocoris obsoletus; $(10,14)$ P. parandinus; $(11,15)$ P. rubrescens; $(12,16) \mathbf{P}$. rubrovenosus.

\section{Phytocoris bergrothi Reuter, 1892 \\ Figs 2, 6, 18}

Anéis esclerosados (Fig. 2). Aproximadamente triangulares, área central ampla; margens largas, sobretudo as anteriores e medianas, com espessamento largo, longo; as posteriores mais estreitas que as laterais. Comprimento máximo 0,264 ; largura máxima 0,432 ; distância entre anéis 0,384 . Placa labiada dorsal, 
comprimento máximo 0,312; largura máxima 0,960.

Parede posterior (Fig. 6). Estruturas A estreitas, alongadas; margens laterais e ventrais ligeiramente irregulares; margem dorsal estreita; processo dorsal largo, fortemente esclerosado, tocando à estrutura $\mathrm{B}$; esta fortemente esclerosada, muito larga lateralmente, na região anterior; entre esta última e a posterior, uma constrição, medianamente; região posterior arredondada; estrutura $\mathrm{E}$ muito estreita. Comprimento máximo 0,240; largura máxima 0,720; estrutura B, comprimento máximo 0,192; largura máxima 0,216.

Placa esclerosada das gonapófises (Fig. 18). Lobos laterais largos na base, estreitando-se para o ápice; lobos dorsal e ventral membranosos. Comprimento máximo 0,192; largura máxima 0,576.

Material examinado. Seis fêmeas. BRASIL: Minas Gerais, Águas Claras, XII-1983, Alvarenga leg. (dois exemplares, Coleção J.C.M. Carvalho); Carmo do Rio Claro, IX-1947, Carvalho leg. (dois exemplares, MNRJ); Bahia, Fruhstorfer leg., Museu Paris, COOLL. Noualhier 1880 (um exemplar MNRJ); São Paulo, Serra da Bocaina, 1650m, São José do Barreiro, XI-1968, Alvarenga \& Seabra leg. (um exemplar, MNRJ).

Distribuição geográfica: BRASIL.

Comentário. Os anéis esclerosados e principalmente a parede posterior separam perfeitamente Phytocoris bergrothi das outras espécies.

\section{Phytocoris irroratus Blanchard, 1852.}

Figs 3, 7, 19

Anéis esclerosados (Fig. 3). Ovais, margens uniformente estreitas. Comprimento máximo 0,120; largura máxima 0,192; distância entre anéis 0,456. Placa labiada dorsal com três regiōes, horizontalmente distintas: região anterior, pouco esclerosada, estreita lateralmente, larga, medianamente, a borda interna sinuosa; região intermediária, membranosa, muito larga lateralmente, estreita medianamente; região posterior, mais larga lateralmente que a correspondente na região anterior, pouco esclerosada medianamente, fortemente esclerosada da metăde da borda lateral da placa, até abaixo da margem posterior dos anéis. Comprimento máximo 0,288; largura máxima 1,152.

Parede posterior (Fig. 7). Estruturas A com pequena reentrância na margem ventral, medianamente; margens laterais arredondadas; margem dorsal estreita; mais larga e fortemente esclerosada nos ângulos laterais; estrutura B esclerosada, larga nas extremidades, ligeiramente mais estreita medianamente; região anterior envolvida numa área membranosa. Comprimento máximo 0,336; largura máxima 0,648 ; estrutura B, comprimento máximo 0,288 ; largura máxima 0,072 .

Placa esclerosada das gonapófises (Fig. 19). Lobos laterais pouco esclerosados, situados sobre duas estruturas, em forma de gancho, fortemente esclerosadas; lobo dorsal estreito e curto; lobo ventral indefinido. Comprimento máximo 0,408; largura máxima 0,720. 

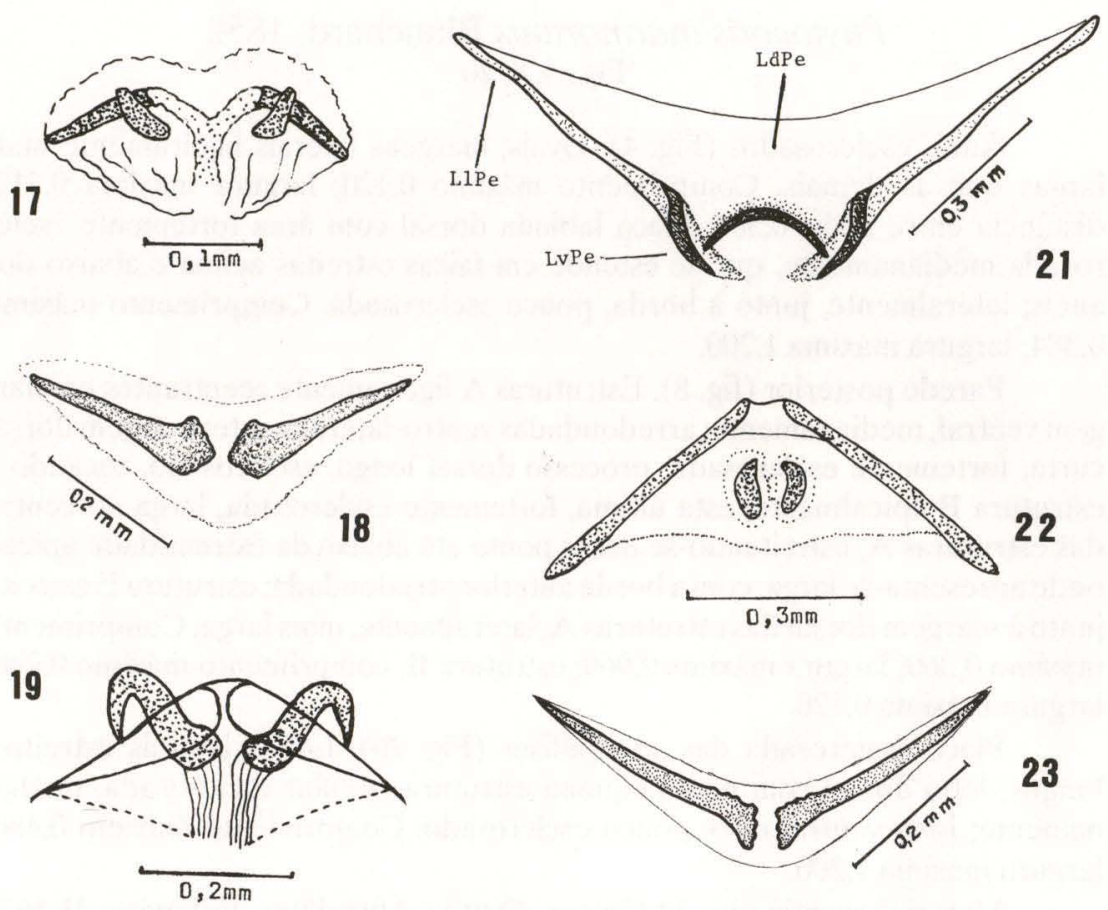

23
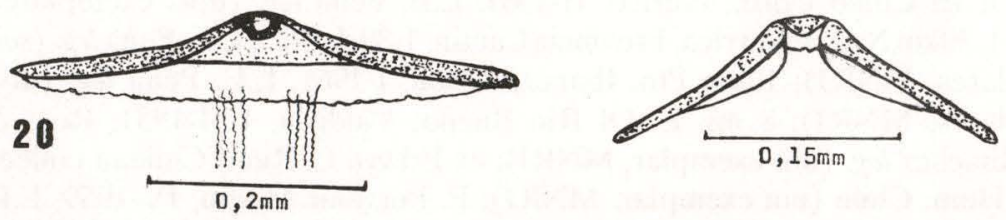

24

Figs 17-24. Placa esclerosada das gonapófises anteriores. (17) Phytocoris araucanus; (18) P. bergrothi; (19) P. irroratus; (20) P. marmoratus; (21) P. obsoletus; (22) P. parandinus; (23) P. rubrescens; (24) P. rubrovenosus.

Material examinado. Nove fêmeas. CHILE: Valle dos Piuquenes, Rio Branco, Aconcagua, Feb. 7-12-II-1964, L.E. Peñaleg. (três exemplares, MNRJ); Maleco, Gutierrez leg. (um exemplar, MNRJ); Santiago, El Canelo, 12-29-X1964, L.E. Peña leg. (um exemplar, MNRJ); E.A. Champin, Pto. Montt. 20II-1945 (um exemplar, MNRJ); Las Cruces Cord. Parral, XI-1960, L.E. Peña leg. (um exemplar, MNRJ). ARGENTINA: Catamarca, El Rodeo, 1500m, I-1959, R. Golbach leg. (um exemplar, MNRJ).

\section{Distribuição geográfica. ARGENTINA, CHILE.}

Comentário. Os anéis esclerosados, a placa labiada dorsal e sobretudo, a placa esclerosada das gonapófises anteriores apresentam características que diferenciam Phytocoris irroratus Blanchard das demais espécies. 


\section{Phytocoris marmoratus Blanchard, 1852}

Figs 4, 8, 20

Anéis esclerosados (Fig. 4). Ovais; margens laterais ligeiramente mais largas que as demais. Comprimento máximo 0,120; largura máxima 0,312; distância entre anéis 0,384 . Placa labiada dorsal com área fortemente esclerosada medianamente, que se estende em faixas estreitas acima e abaixo dos anéis; lateralmente, junto à borda, pouco esclerosada. Comprimento máximo 0,384; largura máxima 1,200.

Parede posterior (fig. 8). Estruturas A ligeiramente reentrantes na margem ventral, medianamente; arredondadas ventro-lateralmente; margem dorsal curta, fortemente esclerosada; processo dorsal longo, esclerosado, tocando a estrutura B apicalmente, esta última, fortemente esclerosada, larga no centro das estruturas A, estreitando-se desse ponto até abaixo da extremidade apical, onde apresenta-se larga, com a borda anterior arredondada; estrutura E estreita junto à margem dorsal das estruturas $\mathrm{A}$; lateralmente, mais larga. Comprimento máximo 0,360 ; largura máxima 0,960 ; estrutura $B$, comprimento máximo 0,240 ; largura máxima 0,120 .

Placa esclerosada das gonapófises (Fig. 20). Lobos laterais estreitos, longos; lobo dorsal com uma pequena estrutura circular esclerosada, medianamente; lobo ventral raso, pouco esclerosado. Comprimento máximo 0,480; largura máxima 1,200.

Material examinado. 30 fêmeas. CHILE: Afunalhue, Villarrica, II-1977 (14 exemplares, MNRJ); Atacalco, I-1952, L.E. Peña leg. (um exemplar, MNRJ); El Coigo Cord., Gurico, II-1961, L.E. Peña leg. (dois exemplares, MNRJ); $30 \mathrm{~km}$ N.E. Villarrica, Provincia Cautin, 1-30-I-1965, L.E. Peñaleg. (seis exemplares, MNRJ); 10km Pto. Ibanez, Aysen, I-1961, L.E. Peña leg. (dois exemplares, MNRJ); 8 mi. E. Of Rio Bueno; Valdivia, 15-I-1951, Ross \& Michelbacher leg. (um exemplar, MNRJ); ex Edwyn C. Reed Chilean collect. Sinop Hem. Chile (um exemplar, MNRJ); F. Porvenir Maipu, IV-1959, L.E. Peña leg. (um exemplar, MNRJ); Santiago, Carvalho leg. (dois exemplares, MNRJ).

Distribuição geográfica. CHILE.

Comentário. A forma alongada e as margens dos anéis esclerosados, a placa labiada dorsal fortemente esclerosada, sobretudo medianamente, e a placa esclerosada das gonapófises anteriores diferenciam Phitocoris marmoratus das demais espécies.

\section{Prhytocoris obsoletus Blanchard, 1852}

Figs 9, 13, 21

Anéis esclerosados (Fig. 9). Longos, área central ampla; margens anterior e posterior estreitas; as laterais e medianas, ligeiramente mais largas. Comprimento máximo 0,168; largura máxima 0,648; distância entre anéis 0,744. Placa labiada dorsal longa, acentuadamente curva, com a borda lateral escle- 
rosada. Comprimento máximo 0,360; largura máxima 1,680.

Parede posterior (Fig. 13). Estruturas A escavadas na margem ventral, medianamente; margem dorsal larga, em forma de arco, até as proximidades da estrutura B; esta larga, arredondada, na região posterior; estreita anteriormente, onde está envolvida numa área membranosa contendo pontículos esclerosados; estrutura $\mathrm{E}$ longa e larga. Comprimento máximo 0,432; largura máxima 1,032; estrutura B, comprimento máximo 0,288; largura máxima 0,120.

Placa esclerosada das gonapófises (Fig. 21). Lobos laterais longos; amplamente largos, fortemente esclerosados; lobo dorsal raso, pouco esclerosado; lobo ventral escavado amplamente, com a borda fortemente esclerosada, contendo lateralmente, as extremidades opostas dos lobos laterais. Comprimento máximo 0,648; largura máxima 1,200.

Material examinado. Três fêmeas. CHILE: El Coigo, Cord. Gurico, II1961, L.E. Peña leg. (um exemplar, MNRJ); Dalcahue, II-1961 L.E. Peña leg. (um exemplar, MNRJ); 30km N.E. Villarrica, Provincia Cautin, 1-30-I-1965 (um exemplar, MNRJ).

\section{Distribuição geográfica. CHILE.}

Comentário. Forma, dimensões, distância entre os anéis esclerosados, curvatura acentuada da placa labiada dorsal; dimensões e características da parede posterior e da placa esclerosada das gonapófises anteriores destacam Phitocoris obsoletus das demais espécies.

\section{Prhytocoris parandinus Carvalho \& Ferreira, 1969}

Figs 10, 14, 22

Anéis esclerosados (Fig. 10). Pequenos, ovais; margens largas, as medianas ligeiramente espessadas. Comprimento máximo 0,120; largura máxima 0,216 ; distância entre anéis 0,480 . Placa labiada dorsal com uma faixa fortemente esclerosada, larga, atingindo toda a borda anterior da placa, margens anteriores dos anéis e, formando uma ponta, que se estende para fora da placa, anteriormente; presença dos lobos laterais das gonapófises anteriores situados obliquamente sobre a placa, atingindo as proximidades da borda anterior dessa última. Comprimento máximo 0,264; largura máxima 1,080.

Parede posterior (Fig. 14). Estruturas A estreitas; margem ventral ligeiramente reentrante, medianamente; levemente arredondadas ventro-lateralmente; margem dorsal esclerosada; estrutura B esclerosada, bilobada no centro das estruturas $\mathrm{A}$, seguida de uma constrição ao nível da margem dorsal; região anterior larga, alongada, com expansões laterais esclerosadas, em cujos bordos laterais ligam-se lobos membranosos, longos; processo dorsal estreito, esclerosado, atingindo a estrutura $\mathrm{B}$; estrutura $\mathrm{E}$ curta, estreita. Comprimento máximo 0,288 ; largura máxima 0,744 ; estrutura $\mathrm{B}$, comprimento máximo 0,264 ; largura máxima 0,192.

Placa esclerosada das gonapófises (Fig. 22). Lobos laterais longos, estreitos, esclerosados; lobo dorsal formado pelas extremidades dos bordos laterais; 
lobo ventral membranoso, com duas pequenas estruturas esclerosadas, em forma de grãos, situadas entre os lobos dorsal e ventral, medianamente. Comprimento máximo 0,192; largura máxima 0,720 .

Material examinado. Quatro fêmeas. CHILE: Coquimbo, IX-1952, Kuschel leg. (dois exemplares, parátipos, MNRJ); Caldera, Atacama, IX-1952 (dois exemplares, parátipos, MNRJ).

Distribuição geográfica. CHILE, Coquimbo.

Comentário. As características morfológicas dos anéis esclerosados, placa labiada dorsal, parede posterior e placa esclerosada das gonapófises anteriores distinguem Phitocoris parandinus das demais espécies.

\section{Prhytocoris rubrescens Blanchard, 1852}

Figs $11,15,23$

Anéis esclerosados (Fig. 11). Pequenos, ovais; área central pequena; muito afastados entre si; margens medianas muito mais longas e largas que as demais; um espessamento largo, esclerosado, se estende sobre parte das margens anteriores, laterais e à borda labiada dorsal. Comprimento máximo 0,072; largura máxima 0,144 ; distância entre anéis 0,456 . Placa labiada dorsal estreita, longa, com áreas esclerosadas lateralmente, ao redor dos anéis, mediana e anteriormente. Comprimento máximo 0,168; largura máxima 0,768.

Parede posterior (Fig. 15). Estruturas A largas lateralmente; margem ventral proeminente; margem dorsal larga, fortemente esclerosada nos ângulos laterais; processo dorsal longo, largo, fortemente esclerosado, tocando a estrutura B, anteriormente; estrutura B larga, arredondada posteriormente, estreitando-se entre a margem dorsal das estruturas A e a região apical; esta larga, lateralmente, estreita anteriormente e envolvida por um lobo longo, largo, membranoso; estrutura $\mathrm{E}$ larga, lateralmente, estreita sob a margem dorsal das estruturas A. Comprimento máximo 0,288; largura máxima 0,744; estrutura B, comprimento máximo 0,144; largura máxima 0,096.

Placa esclerosada das gonapófises (Fig. 23). Lobos laterais longos, esclerosados; lobo dorsal membranoso; lobo ventral membranoso curto, formado pelas extremidades opostas dos lobos laterais. Comprimento máximo 0,208; largura máxima 0,565 .

Material examinado. Cinco fêmeas. CHILE: ex Edwyin C. Reed Chilean collect. Sinop. Hem. Chile (um exemplar, MNRJ); Rio Blanco, 15-XII-1917, Herbster leg. (um exemplar, MNRJ); Santiago, Sn. Bernardo, N. Kormiler leg., 25-IX-1949 (um exemplar, MNRJ); Santiago, XI-1952, Kuschel leg. (um exemplar, MNRJ); Santiago, Carvalho leg. (um exemplar comparado com o tipo, na Coleção Carvalho).

Distribuição geográfica. CHILE.

Comentário. Os anéis esclerosados, a placa labiada dorsal e a parede posterior diferenciam Phitocoris rubrescens das demais espécies. 


\section{Prhytocoris rubrovenosus Carvalho \& Ferreira, 1969}

Figs 12, 16, 24

Anéis esclerosados (Fig. 12). Alongados, ligados entre si por um prolongamento esclerosado das margens anteriores e medianas. Comprimento máximo 0,096; largura máxima 0,384; distância entre anéis 0,504. Placa labiada dorsal com um espessamento extenso, fortemente esclerosado à frente dos anéis, mais largo sobre as margens anteriores e muito estreito ao nível das margens medianas; as bordas laterais e posteriores da placa, fortemente esclerosadas. Comprimento máximo 0,336; largura máxima 1,440.

Parede posterior (Fig. 16). Estruturas A levemente reentrantes na margem ventral, medianamente; arredondadas ventro-lateralmente; margem e processo dorsais, fortemente esclerosados; estrutura B alongada, larga ao nível da margem dorsal das estruturas A e na extremidade apical; esta, levemente incisa, dá origem a dois pequenos lobos, lateralmente; abaixo desses últimos, dois lobos longos, pouco esclerosados, com espessamento fortemente esclerosado na base; estrutura $\mathrm{E}$ estreita junto à margem dorsal das estruturas $\mathrm{A}$, larga lateralmente. Comprimento máximo 0,504; largura máxima 0,960 ; estrutura $\mathrm{B}$, comprimento máximo 0,212 ; largura máxima 0,175 .

Placa esclerosada das gonapófises (Fig. 24). Lobos laterais curtos, largos, com áreas fortemente esclerosadas e claras. Comprimento máximo 0,360; largura máxima 0,960 .

Material examinado. 12 fêmeas. CHILE: Afunalhue, Villarrica, XII-1977 (nove exemplares, MNRJ); Santiago, Carvalho leg. (um exemplar, parátipo, na Coleção Carvalho); Santiago, G. Mann leg. (um exemplar, Coleção Carvalho); Valdivia, I-1980 (um exemplar, Coleção Carvalho).

Distribuição geográfica. CHILE, Santiago.

Comentário. A forma alongada e estreita dos anéis esclerosados; a placa labiada dorsal, com a faixa esclerosada à frente dos anéis; a parede posterior e a placa esclerosada das gonapófises anteriores diferenciam Phitocoris rubrovenosus Carvalho \& Ferreira das demais espécies.

AGRADECIMENTOS. Registra-se aqui os melhores agradecimentos ao CNPq pela concessão da Bolsa de Pesquisa que muito tem auxiliado a realizar nossas pesquisas entomológicas; ao Dr. José C.M. Carvalho pela cessão de espécimens de Miridae utilizados nesta pesquisa e também pela leitura crítica do presente manuscrito e à Professora Andréa Khouri pela eficiente colaboração nas ilustrações do trabalho.

\section{REFERÊNCIAS BIBLIOGRÁFICAS}

BLANCHARD, E. 1852. Miridae, p.183-199. In: GAY (ed.). Hist. Fis. Pol. Chile. Paris, 7: 113-238.

CARVALHO, J.C.M. 1959. A Catalogue of the Miridae of the World. Part IV. Subfamily Mirinae. Arq. Mus. Nac., Rio de Janeiro, 48: 383p. 
CARVALHO, J.C.M. \& I.P.GOMES. 1970. Mirídeos Neotropicais CXIV: Algumas espécies de Phytocoris Fallén da Argentina, Brasil, Colômbia e Paraguai (Hemiptera). Rev. Brasil. Biol., Rio de Janeiro, 30 (1): 115-135.

CARVALHO, J.C.M. \& P.S.F. FERREIRA. 1969. Mirídeos Neotropicais, CXI: Gênero Phytocoris Fallén na Fauna Chilena (Hemiptera). An. Acad. brasil. Cienc., Rio de Janeiro, 41 (4): 601-623.

DAVIS, N.T. 1955. Morphology of the female organs of reproduction in the Miridae (Hemiptera). Ann. ent. Soc. Am., Columbus, 48 (3): 132-150.

FALLÉN, C.F. 1814. Specimen novam Hemiptera disponendi methodum exhibens. Lundae, 26p.

FONTES, A.V. 1981. Estudos comparativos da genitália da fêmea do gênero Notholopus Bergroth, 1922 (Hemiptera, Miridae). Arq. Mus. Nac., Rio de Janeiro, 56: 137-183.

- 1989. Contribuição ao estudo da genitália da fêmea de algumas espécies de Prepops Reuter, 1905 (Hemiptera, Miridae). Bol. Mus. Nac., Rio de Janeiro, n.s. Zool. 330: 1-31.

REUTER, O.M. 1892. Voyage de M.F. Simon au Venezuela (december 1887avril 1888) 20e. memoire. Hémiptères. Ire. partie. Capsides. Ann. Soc. Ent. Fr., Paris, 61: 392-402.

SLATER, J.A. 1950. An Investigation of the Female Genitalia as Taxonomic Characters in the Miridae (Hemipitera). Iowa St. Cool. J. Sci., Ames, 26 (1): $1-82$.

Recebido em 15.X.1993; aceito em 22.II.1994. 